\title{
Study of choice between accident and emergency departments and general practice centres for out of hours primary care problems
}

\author{
Sajjad F Rajpar, Michelle A Smith, Matthew W Cooke
}

\begin{abstract}
Objectives-To determine the reasons for choosing between primary care out of hours centres and accident and emergency (A\&E) departments for patients with primary care problems.

Methods-Interviews using a semistructured approach of samples of patients attending $A \& E$ departments and general practitioner (GP) out of hours centres for primary care problems.

Results-102 patient interviews were undertaken. Sixty two per cent of $A \& E$ attenders were unemployed compared with $41 \%$ of out of hours attenders. White people were more likely to attend $A \& E$ departments and Asians the out of hours centre $(p<0.01)$ and unemployed were more likely to attend $\mathrm{A} \& \mathrm{E}$ departments (70\% $v 30 \%)$. Some $46.3 \%$ of A\&E department attenders had not contacted their GP before attending; $81.3 \%$ of first time users of the out of hours centre found out about it on the day of interview. Those attending $A \& E$ thought waiting times at the out of hours centre would be 6.3 hours (median) compared with a median perceived time of 2.9 hours by those actually attending the out of hours centre. Actual time was actually much less.

Conclusion-Once patients have used the GP out of hours centre they are more likely to use it again. Education should be targeted at young adults, the unemployed and white people. Patients should be encouraged to contact their GP before $A \& E$ department attendance for non-life threatening conditions. Waiting time per-
\end{abstract}

ception may be an important reason for choice of service.

(F Accid Emerg Med 2000;17:18-21)

Keywords: out of hours care; primary care; patient choice

General practice cooperatives are a comparatively new and successful provision of out of hours primary care in the United Kingdom. In these cooperatives groups of general practitioners (GPs) combine resources to provide emergency cover for their practices. Out of hours they usually run an emergency centre. Patients who telephone the GPs may be given advice, advised to attend the centre, or may receive a visit. However, patients continue to attend the accident and emergency (A\&E) department with primary care problems out of hours. As primary care attenders to the A\&E department can be managed more appropriately and more economically by the GP services, ${ }^{1}$ the current state of affairs represents a poor use of resources.

Factors that have been shown to determine why patients choose $A \& E$ over general practice are travelling distance, ${ }^{2}$ lack of knowledge of the range of GP services, ${ }^{3}$ perceived need for immediate attention, ${ }^{4}$ and more advanced technology. ${ }^{5}$ A small proportion of these patients are not registered with a GP, are visitors, or are homeless. ${ }^{6}$ These results are from studies that were conducted before the inception of out of hours GP cooperatives, when GP deputising services were the mainstay of out of hours primary care. No study to date has determined the reasons for out of
University of Birmingham S F Rajpar M A Smith

Primary Care Unit, University of Warwick and Walsgrave Hospitals NHS Trust, Coventry

$\mathrm{M}$ W Cooke

Correspondence to: Dr M W Cooke, Senior

Lecturer in Emergency Care, Emergency Medicine Research Group, Centre for Primary Health Care Studies, University of Warwick,

Coventry CV4 7AL

(e-mail:

MWCooke@emerg-uk.com)

Accepted 14 September 1999

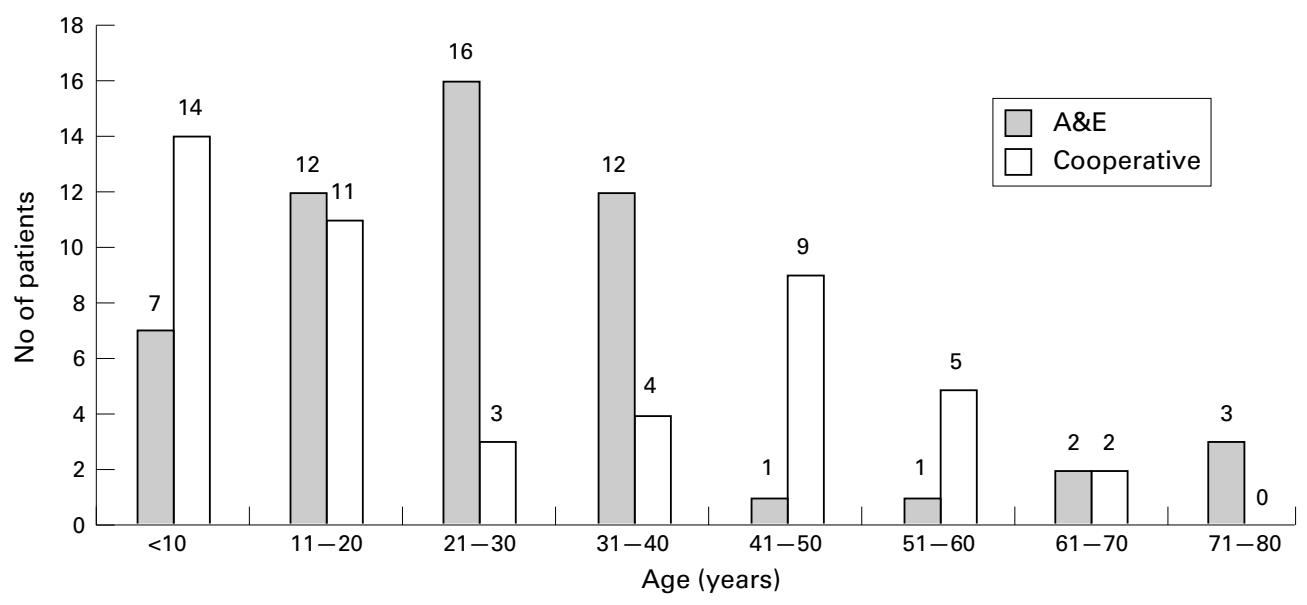

Figure 1 The age distribution of $A \mathcal{E} E$ and cooperative patients. 
Table 1 A summary of employment status and ethnicity division between $A \mathcal{E} E$ and $G P$ cooperatives

\begin{tabular}{lll}
\hline & \multicolumn{2}{l}{$\begin{array}{l}\text { No (\%) of each category } \\
\text { attending each provider }\end{array}$} \\
\cline { 2 - 3 } & $\begin{array}{l}\text { AEE } \\
(n=54)\end{array}$ & $\begin{array}{l}\text { Cooperative } \\
(n=48)\end{array}$ \\
\hline $\begin{array}{ll}\text { Employment } \\
\quad \text { Employed }\end{array}$ & $13(50)$ & $13(50)$ \\
$\quad$ Unemployed & $21(70)$ & $9(30)$ \\
$\quad$ Student/retired adult & $20(43)$ & $26(57)$ \\
Ethnicity & $33(69)$ & $15(31)$ \\
$\quad$ White & $10(29)$ & $25(71)$ \\
Asian & $11(58)$ & $8(42)$ \\
Black & & \\
\hline
\end{tabular}

Table 2 Reasons for attending $A \mathcal{E} E$ with primary care problem

\begin{tabular}{ll}
\hline Reason & No (\%) $(n=54)$ \\
\hline "GP was closed" & $27(50.0)$ \\
Tried to contact GP & $2(3.7)$ \\
Did not try to contact GP & $25(46.3)$ \\
Perceived severity of problem & $12(22.2)$ \\
Did not want to disturb GP & $6(11.1)$ \\
Wanted second opinion & $4(7.4)$ \\
Perceive wait at A\&E < cooperative & $3(5.6)$ \\
Perceived that facilities and & $2(3.7)$ \\
$\quad$ investigations better at A\&E & \\
\hline
\end{tabular}

hours A\&E attendance by primary health care patients in the "era of the cooperative".

\section{Methods}

Using a semistructured questionnaire, two groups of patients were interviewed. One group had self presented to the A\&E department out of hours with primary care problems; the other group consisted of primary care patients attending the GP cooperative out of hours. Patient volunteers were recruited using quota sampling on a first come basis from the waiting areas of the $\mathrm{A} \& \mathrm{E}$ department or the GP cooperative, both located at the same site in a socially deprived area in west Birmingham. At the time of the study, the GP cooperative had been functioning for almost 24 months

Table 3 Knowledge of GP emergency service of $A \mathcal{E} E$ primary care attenders

\begin{tabular}{|c|c|c|}
\hline \multirow[b]{2}{*}{ Question asked } & \multicolumn{2}{|c|}{ No $(\%)(n=54)$} \\
\hline & Yes & No \\
\hline "Do you know your GP's out of hours arrangements?" & $43(79.6)$ & $11(20.4)$ \\
\hline "Do you know about the GP cooperative upstairs?" & $3(5.6)$ & $51(94.4)$ \\
\hline "Have you used this GP cooperative before?" & $2(3.7)$ & $52(96.3)$ \\
\hline "Would you used the GP cooperative in the future?" & $45(83.3)$ & $9(16.7)$ \\
\hline
\end{tabular}

Table 4 How GP cooperative users found out about service

\begin{tabular}{lll}
\hline & \multicolumn{2}{l}{ No (\%) (n=48) } \\
\cline { 2 - 3 } Question asked & Yes & No \\
\hline "Found out about cooperative on day of interview" & $35(72.6)$ & $13(27.1)$ \\
First time users of cooperative on day of interview & $39(81.3)$ & $9(23.7)$ \\
GP preference: & $15(31.3)$ \\
$\quad$ Would have preferred to see own GP & $30(62.5)$ \\
$\quad \begin{array}{l}\text { Indifferent } \\
\text { Would not have preferred to see own GP }\end{array}$ & $3(6.3)$ \\
\hline
\end{tabular}

Table 5 Perception of waiting time compared with actual waiting time

\begin{tabular}{llll}
\hline & $\begin{array}{l}\text { Median perceived waiting time at } \\
\text { the cooperative by both } A \mathcal{E} E \text { and } \\
\text { cooperative patients }(h)\end{array}$ & $\begin{array}{l}\text { Median actual waiting } \\
\text { time of patient at their } \\
\text { location }\end{array}$ & $\begin{array}{l}\text { p Value } \\
\text { (Mann-Whitney) }\end{array}$ \\
\hline A\&E & 6.3 & 2.61 & $<0.00001$ \\
Cooperative & 2.9 & 1.17 & $<0.001$ \\
\hline
\end{tabular}

and was consulting around 80 to 100 patients per week (personal communication).

At the A\&E department, patients with primary care problems (defined as patients with non-emergency problems that could be managed in an average local GP surgery ${ }^{7}$ and triaged not to require treatment within two hours $^{8}$ ) were recruited to this study. At the GP cooperative, all attenders were included; they had all received telephone advice from the emergency GP and were subsequently requested to attend the primary care centre. This excluded those patients who only required telephone advice and those who were visited at home. Interviewing took place during 12 three hour "out of hours" sessions (six sessions at each site) over a period of two months between February and April 1998. Analysis was performed using the SPSS package.

\section{Results}

A total of 54 patients attending the $A \& E$ department and 48 patients attending the GP cooperative were interviewed. The proportion of men and women interviewed at each site was not significantly different $(26(48 \%)$ men and 28 women in A\&E; 19 (40\%) men and 29 women in the GP cooperative; $\chi^{2}$ with Yates's correction $=1.12, p=0.29$ ). Figure 1 shows the age distribution of those attending the $A \& E$ and the cooperative. The mean age of $A \& E$ attenders was 27.9 years (95\% confidence intervals (95\% CI) 10.4 to 45.4$)$ and that of cooperative attenders was 25.4 years $(95 \% \mathrm{CI}$ 4.8 to 46.0 ).

Table 1 summarises the ethnicity and employment status of the patients. There was an association between the site attended and the ethnic group, $\left(\chi^{2}=13.35, \mathrm{p}<0.01\right)$ with white patients more likely to attend the $A \& E$ and Asian patients tending to choose the cooperative. Unemployed patients were more likely to attend $\mathrm{A} \& \mathrm{E}(70 \%$ v $30 \%)$, although there was no significant difference because of the small sample size. Table 2 summarises the reasons given by $A \& E$ patients with primary health care problems for choosing to attend $\mathrm{A} \& \mathrm{E}$ out of hours rather than contacting their GP. Table 3 summarises the knowledge and use of out of hours services by A\&E patients.

Table 4 summarises the methods by which cooperative attenders discovered this service. Table 5 summarises actual patient waiting times at the A\&E department and at the cooperative as well as the perceived GP cooperative waiting times by both patient groups.

\section{LIMITATIONS TO THE STUDY}

The sample size in this pilot study was small. However, important significant results have been revealed that we believe warrant early reporting. Primary care patients are those with non-emergency problems that can be managed by an "average local GP". ${ }^{7}$ This classification is widely debated. ${ }^{9}$ The cooperative and the A\&E department were both located at the same site, in a deprived inner city area, which is not representative of all localities. This may be a limitation to the generalisability of the results. All those attending the out of hours centre have 
been screened by a telephone call to the GP, whereas A\&E attenders self present without any prior consultation.

\section{Discussion}

This is the first study in the United Kingdom to determine the characteristics of out of hours primary care attenders to $\mathrm{A} \& \mathrm{E}$ and also of primary care attenders to GP cooperatives, about whom minimal information is currently available. Important new reasons for choice of emergency care facility have been detected.

The largest group of out of hours primary care attenders to present to the A\&E department were young adults (21-40 year age group; see fig 1$)$. The majority $(50 \%)$ was unaware of the out of hours arrangements of their GP. The small number $(3.7 \%)$ of $A \& E$ patients that had attempted to contact their GP before attending the $\mathrm{A} \& \mathrm{E}$ department is consistent with past studies, which report values between $3-6 \% .{ }^{10}$ The most frequent users of the GP cooperative were $0-20$ years old, and the majority of GP cooperative attenders had found out about its service on the day of their interview while participating in this study. This suggests that primary care in the community is readily available and obtaining it is not difficult, providing it is sought.

This study demonstrates that there exists a considerable misunderstanding concerning the role of the GP and highlights the pressing need to educate the public, especially young adults, about their GP's out of hours arrangements and how to access these services if required. There is a general consensus that such education would be best undertaken by a GP known to the patient before an out of hours situation arises. ${ }^{11}$ This study found that most of the primary care A\&E attenders, once informed about the GP cooperative service during the interview, would be willing to use the GP cooperative in the future. Our results suggest that any such education would be best targeted to young white adults (aged 21-30). This age group attends the GP least frequently suggesting that there may a need to provide education about out of hours primary care services at $\mathrm{A} \& \mathrm{E}$ departments.

All patients, who had previously used the GP cooperative, regardless of the site at which they were interviewed, were satisfied with their previous experience. In addition, a greater proportion of the patients at the GP cooperative compared with the A\&E department had used this service before, and thus were "reusing" it. This evidence is encouraging and suggests that the cooperative, with its high satisfaction and ease of accessibility will probably be used increasingly in the future and become an important service as its public awareness increases.

Primary care attenders to A\&E perceived that the waiting time for a GP consultation at the cooperative would be longer than the actual waiting time that they endured at the $A \& E$ department. This correlates with the findings of Cragg et al that patients commonly perceive that $\mathrm{A} \& \mathrm{E}$ is a quicker service compared with the GP services. ${ }^{12}$ Other authors have reported that a shorter waiting time for an out of hours visit is significantly correlated with satisfaction ${ }^{713}$; this may explain the high rate of satisfaction as measured by the majority $(83.3 \%)$ who would use the cooperative again. GP cooperative attenders expected to wait longer at the cooperative than they actually did. It is encouraging that the mean waiting time at the GP cooperative was shorter than the mean waiting time at the $\mathrm{A} \& \mathrm{E}$ department and also shorter than patients' perceived GP cooperative waiting time.

Both $\mathrm{Zola}^{14}$ and Mechanic ${ }^{15}$ emphasise that the perceived severity of illness by patients has an important role in influencing the decision making process with regards to seeking medical aid (Health Belief Model). Despite knowing about the out of hours GP services, patients will continue to attend $\mathrm{A} \& \mathrm{E}$ if they perceive their problems to be severe. Some authors regard these reasons for attending $A \& E$ as "genuine". ${ }^{11}$ Such primary care patients attending the A\&E department comprised $22.2 \%$ in this study, lower than reported in other studies. ${ }^{11} 16$ This is perhaps a reflection of the different case mixes in these studies. However, Helman ${ }^{17}$ has noted that the perceived severity of illness by the public and health professionals tends to differ greatly, particularly with regard to the significance of symptoms.

A minority (4\%) of the primary care patients attending A\&E believed that the quality of health service was superior in a hospital setting because of more advanced investigative equipment and expertise. Although A\&E doctors are more likely than GPs to carry out more investigations and prescribe more medication to primary care patients, there does not seem to be a significant effect on the outcome. ${ }^{7}$ Perhaps over-investigation by A\&E doctors may artificially reinforce patients' belief that they require $\mathrm{A} \& \mathrm{E}$ care rather than primary care.

Previous studies have determined that the use of primary care medical services bears an inverse relation to the travelling distance from the patient's abode, as well as individual transport difficulties. In this study, travelling distance was not a factor in the choice as the $\mathrm{A} \& \mathrm{E}$ department and the cooperative are both located at the same site. NHS Direct, a telephone advice service, has not yet been shown to have any effect on either A\&E or GP attendance. ${ }^{18}$

In conclusion, this study highlights that there is a lack of knowledge among primary care attenders to $\mathrm{A} \& \mathrm{E}$ with regards to the specific out of hours arrangements of their GP. There is thus a need for providing better education to patients about GP out of hours services, though it has yet to be determined the place and method most appropriate to do so. Clearly, further research is required in this area using studies with a larger sample size from differing socioeconomic backgrounds.

We would like to thank Dr Sue Wilson for her constructive comments on study design and on the manuscript. We would like to thank the staff of the Accident and Emergency like to thank the staft of the Accident and Emergency
Department, City Hospital, Birmingham and the Primary Care Centre for their support.

Conflict of interest: none.

Funding: none. 
Contributors

All three authors were closely involved in the design of the study, interpretation of the SR undertook the interviews and collated the data and wrote the initial draft of the paper. MWC initiated and coordinated the original idea of the study and is guarantor of the paper.

1 Dale J, Lang H, Roberts JA, et al. Cost effectiveness of treating primary care patients in accident and emergency: a comparison between general practitioners, senior house officers, and registrars. BMF 1996;312:1340-4.

2 Walsh M. Geographical factors and A\&E attendance. Nursing Standard 1990;15:28-31.

3 Dale J, Green J, Glucksman E, et al. Providing for primary care: progress in $A \mathcal{E} E$. London: Department of Accident and Emergency Medicine, King's College Hospital, 1991.

4 Warren R. The other 99 percent. The Health Service fournal 1989;99:232-3.

5 Steel J. Inappropriate-the patient or the service? Accid Emerg Nurs 1995;3:146-9.

6 Prince M, Worth C. A study of 'inappropriate' attendances to a paediatric accident and emergency department. F Public Health Med 1992;14:177-82.

7 Dale J, Green J, Reid F, et al. Primary care in the accident and emergency departments: I. Prospective identification of patients. BMF 1995;311:427-30.

8 Manchester Triage Group. Emergency triage. In: MackwayJones K, ed. Manchester triage book. London: BMJ Publishing Group, 1997
9 Lowy A, Kohler B, Nicholl J. Attendance at accident and emergency departments: unnecessary or inappropriate? $\mathcal{F}$ Public Health Med 1994;16:134-40.

10 Bowling A, Isaacs D, Armstrong JA, et al. Patient use of a paediatric hospital casualty department in the east end of London. Fam Pract 1987;4:85-90.

11 Partridge MR, Latouche D, Trako E, et al. A national census of those attending UK accident and emergency departments with asthma. f Accid Emerg Med 1997;14:16-20.

12 Cragg DK, Campbell SM, Roland MO. Out of hours primary care centres: characteristics of those attending and declining to attend. BMF 1994;309:1627-9.

13 Dale J, Green J, Reid F, et al. Primary care in the accident and emergency departments II. BMF 1995;311:423-6.

14 Zola I. Pathways to the doctor, from person to patient. Soc Sci Med 1973;7:677-89.

15 Mechanic D. Heath and illness behaviour and patientpractitioner relationships. Soc Sci Med 1992;34:1345-50.

16 Ward P, Huddy J, Hargreaves S, et al. Primary care in London: an evaluation of general practitioners working in an inner city accident and emergency department. 7 Accid Emerg Med 1996;13:11-15.

17 Helman C. Culture health and illness. Oxford: ButterworthHeinemann, 1991 .

18 Munro J, Nicholl J, O'Cathain A, et al. Evaluation of NHS Direct first wave sites. First interim report to the Department of Health. Sheffield: Medical Care Research Unit, 1998. 